\title{
Studi Tentang Kemampuan Teknik Dasar Bulutangkis Siswa Sekolah Dasar
}

\author{
Zarwan, Arsil, Sefri Hardiansyah \\ Universitas Negeri Padang, Indonesia \\ J1. Prof. Dr. Hamka Kampus Air Tawar Padang \\ email: zarwanfik@fik.unp.ac.id, arsil@fik.unp.ac.id, hardiansyah@fik.unp.ac.id
}

\begin{abstract}
ABSTRAK
The problem in this study is the low performance of badminton elementary school students in the Pembangunan Padang city which is likely due to the low basic technical skills of badminton. The purpose of this study was to know concretely about the basic technical skills of badminton owned by elementary school students in the Pembangunan Padang city. This type of research is classified into descriptive research. The population in this study were all students of elementary school students in the Pembangunan Padang city totaling 14 people, the entire population in this study was used as a sample. The instrument used to collect data in this study was to use basic technique tests to play badminton consisting of service, lob and smash. Analysis technique using descriptive statistical analysis. The results showed that: (1) Most elementary school students in Pembangunan Padang City had the ability to serve in the less category. (2) Most elementary school students in Pembangunan Padang City have the ability to lob in the less category. (3) Most elementary school students in Pembangunan Padang City have the ability to smash in good categories. (4) Most elementary school students in Pembangunan Padang City have basic badminton technical skills in the medium category.
\end{abstract}

Kata kunci: teknik dasar, bulutangkis

\section{PENDAHULUAN}

Olahraga merupakan bagian dari aktivitas sehari-hari yang penting dan sudah merupakan kebutuhan bagi manusia dan berguna untuk membentuk jasmani dan rohani yang sehat. Diantara cabang-cabang olahraga yang berkembang di Indonesia, cabang olahraga bulutangkis termasuk dalam salah satu cabang olahraga yang populer di kalangan masyarakat. Olahraga bulutangkis banyak digemari oleh tua dan muda, baik laki-laki maupun perempuan, khususnya di Indonesia. Hal ini dikarenakan pemain bulutangkis disamping mudah dimainkan dan peralatannya pun mudah di dapatkan. Pemahaman tentang nilai-nilai olahraga bulutangkis akan berguna bagi pelakunya, terutama adanya mamfaat yang berkaitan dengan perkembangan fisiologis-anatomis maupun perkembangan fisiologis dan sosiologis. Keberadaan olahraga bulutangkis ditengah-tengah pesatnya perkembangan kegiatan olahraga lainnya patut menjadi perhatian dari berbagai pihak.

Untuk mencapai prestasi yang optimal, ada 4 (empat) komponen yang diperhatikan yakni kondisi fisik, teknik, taktik dan mental (Syafruddin. 2011;78). Disamping keempat komponen ini, terdapat hal yang terpenting dalam sebauh proses pencapaian prestasi, yakni pembinaan prestasi yang dilakukan sejak dini. Dan ini merupakan salah satu indikasi mengapa Indonesia kalah bersaing dengan Negara-negara lain dalam hal keolahragaan, khususnya bulutangkis. Dalam hal ini, Menegpora dalam suatu kesempatan 
mengatakan bahwa dengan pembinaan yang sistematis dan berkesinambungan di tingkat SD dan SMA/SMK prestasi olahraga meningkat. Terutama pembinaan tersebut dilakukan terhadap atlet sejak dini. Tanpa ada pembinaan yang sistematis dan berkesinambungan di tingkat SD sampai SMA/SMK prestasi olahraga secara umum akan mengalami kemunduran dan oleh karena itu, salah satu faktor yang sanngat menentukan adalah pembinaan atlet usia tingkat sekolah dasar. Menurut Purnama dalam Ghazali (2014:3):

"pembinaan olahraga di tingkat klub atau sekolah, pada umumnya dimulai sejak periode usia dini antara usia 6-12 tahun. Eksistensinya sebagai lapisan pembinaan yang berperan untuk melanggengkan proses regenerasi menjadi sangat penting, lebih lebih karena klub dan sekolah merupakan pusat awal pembinaan atlet. Atlet usia dini dan menjadikan salah satu strategi paling mendasar dalam upaya meningkatkan prestasi olahraga".

Faktor lain yang sangat mempengaruhi keberhasilan pencapaian prestasi adalah kemampuan teknik seseorang. Hal ini dijelaskan oleh Bompa (1990:120) bahwa teknik merupakan elemen terpenting dalam pencapaian prestasi. Permasalahan yang terjadi adalah bagaimanakah melatih teknik yang baik bagi atlet usia tingkat sekolah dasar. Pada anak usia tingkat sekolah dasar pelatih harus mampu memilih metode yang menarik bagi anak sehingga anak tidak bosan dalam mengikuti latihan. Sekolah Dasar Pembangunan kota merupakan salah satu sekolah yang menyelenggarakan kegiatan ekstrakurikuler Bulutangkis, namun sejak dilakukannya pembinaan sampai saat ini siswa Sekolah Dasar Pembangunan belum mampu meraih prestasi yang maksimal khususnya pada cabang olahraga bulutangkis, hal ini tentu sangat mengecewakan bagi pihak sekolah, siswa dan juga orang tua. Berdasarkan informasi yang diperoleh dari pelatih kegiatan ektrakurikuler Bulutangkis di Sekolah Dasar Pembangunan diperoleh informasi bahwa masih banyak siswa yang sering melakukan kesalahan dalam pelaksanaan teknik bermain bulutangkis seperti servis, lob dan smash, namun hal ini baru sebatas dugaan atau asumsi, oleh sebab itu untuk membuktikan asumsi tersebut, maka penulis memandang perlu untuk melakukan penelitian dengan harapan hasil penelitian ini dapat mengungkap keadaan sebenarnya tentang kemampuan dasar bermain bulutangkis yang dimiliki oleh para siswa yang bisa menjadi pedoman dan rujukan bagi guru atau Pembina ekstrakurikuler bulutangkis di Sekolah Dasar Bulutangkis.

\section{TINJAUAN PUSTAKA}

\section{Teknik Dasar Bulutangkis}

Dalam permainan bulutangkis, penguasaan tekhnik dasar merupakan salah satu hal yang sangat penting untuk menjadikan seseorang atlet mencapai prestasi maksimal. Ada beberapa tekhnik dasar yang haru dikuasai atlit dalam permainan Bulutangkis yakni, yakni cara memegang raket, cara melakukan pukulan (servis, lob, smes, netting play, drop shot dan drive), posisi dasar dan footwork. Disampinjg itu, sangat dituntut agar berlatih tekun, disiplin, dan terarah dibawah bimbingan pelatih yang berkualifikasi baik, teknik dasar permainan bulutangkis yang perlu dipelajari secara umum dapat dikelompokan kedalam beberapa bagian yaitu: (a) cara memegang raket (grips) (b) Stance (sikap berdiri) (c) Footwork (gerakan kaki) (d) Pukulan (Strokes)".

\section{1) Pegangan Raket (Grip)}

Cara memegang raket bulutangkis sebenarnya cukup mudah, karena bentuk raket yang kecil dan ringan juga mempunyai tempat pegangan (handel). Tetapi dalam permainan tentu kita mencari teknik apa yang baik dipergunakan agar pegang tersebut betul-betul dapat memberikan manfaat bagi yang mempergunakannya, penguasaan teknik 
yang benar akan memudahkan atlet untuk melakukan pukulan dan juga akan menghasilkan arah yang kita kehendaki (tepat pada sasaran). Bagi pemain pemula penguasaan teknik pegangan dengan benar sangat diperlukan, sebab apabila teknik ini tidak dikuasai dengan benar maka akan sulit untuk diperbaiki atau dibetulkan dimasa datang, dan akibatnya akan berpengaruh terhadap keakuratan pukulan. Peganglah raket dengan santai dan lemas dan juga jangan terlalu kuat/tegang sebab akan dapat menghabiskan tenaga tangan yang memegang raket, pegangan ini baru dikuatkan pada saat memukul shuttlecock. Tohar (1992) menjelaskan ada beberapa jenis pegangan yang harus diketahui yakni gablak kasur, pegangan kampak (forehand grip), pegangan backhand dan pegangan kombinasi.

\section{2) Pukulan}

Setelah memahami cara memegang raket seperti yang telah disampaikan, maka sekarang kita akan membahas tentang teknik pukulan yang mengarah pada bagaimana cara melakukkan pukulan dengan baik. Penguasaan teknik pukulan ini sangat diperlukan dalam permainan bulutangkis, bagi pemain pemula teknik pukulan yang diberikan hanya teknik dasar dan ini harus betul-betul dikuasai. Dalam permainan bulutangkis ada beberapa teknik pukulan yang dikuasai oleh pemain antara lain:

\section{a. Servis}

Servis merupakan pukulan pertama sebagai pembuka permainan dan sekarang servis tersebut merupakan serangan pertama yang dilakukan ke pihak lawan. Pentingnya servis ini dapat kita lihat bahwa tanpa servis mustahil permainan dapat berlangsung, dan juga hanya pemain yang melakkan servis saja yang dapt membuat point atau menambah angka, untuk itu servis ini perlu dikuasai oleh seorang pemain bulutangkis dengan baik dan matang. Ada beberapa jenis servis yang perlu dikuasai antara lain: servis pendek dan servis panjang baik dilakukan denagn cara forehand maupun backhand.

\section{b. Lob}

Lob adalah salah satu bentuk pukulan dalam permainan bulutangkis dengan tujuan untuk menerbangkan shuttlecock setinggi mungkin yang mengarah dan jatuh di bagian belakang lapangan lawan. Pukulan lob ini dapat dilakukan dari atas kepala (overhead) maupun dari bawah (underhand) baik dengan forehand maupun dengan backhand. Melihat dari karakteristik dari pukulan lob ini, maka seorang pemain yang sering bermain dengan pukulan lob harus didukung oleh tenaga yang besar dan stamina yang tinggi. Pukulan ini dapat digunakan untuk menyerang dan juga untuk bertahan, dan juga untuk memperlambat tempo permainan sehingga dapat untuk memperbaiki posisi. Alangkah lebih baiknya pukulan lob ini diarahkan secara bervariasi seperti lurus, menyilang ke kiri maupun kanan belakang lapangan lawan.

\section{c. Smash}

Smash merupakan pukulan overhead (atas) yang diarahkan ke bawah dan dilakukan dengan tenaga penuh. Pukulan ini identik sebagai pukulan menyerang. Karena itu tujuan utamanya untuk mematikan lawan. Pukulan smes adalah bentuk pukulan keras yang sering digunakan dalam permainan bulutangkis. Karakteristik pukulan ini adalah; keras, laju jalannya kok cepat menuju Iantai Iapangan, sehingga pukulan ini membutuhkan aspek kekuatan otot tungkai, bahu, lengan, dan fleksibilitas pergelangan tangan serta koordinasi gerak tubuh yang harmonis. Dalam praktek 
http://1ppm.upiyptk.ac.id/ojs3/index.php/MAJALAHILMIAH/index

permainan, pukulan smes dapat dilakukan dalam sikap diam/berdiri atau sambil loncat (King Smash).

\section{METODOLOGI PENELITIAN}

Jenis penelitian ini adalah deskriptif dimana peneliti hanya ingin melihat keadaan sebenarnya di lapangan tentang kemampuan teknik dasar bermain bulutangkis siswa yang mengikuti kegiatan ekstrakurikuler di Sekolah Dasar Pembangunan Kota Padang. populasi dalam penelitian ini adalah seluruh siswa yang mengikuti kegiatan ekstrakurikuler bulutangkis yang berjumlah 14 orang. Seluruh populasi dalam penelitian ini dijadikan sebagai sampel. Untuk mendapatkan data tentang kemampuan teknik dasar bulutangkis maka digunakan instrument tes yang terdiri dari tes servis, lob dan smash untuk usia pemula. Teknik analisis yang digunakan sesuai dengan jenis penelitian yaitu dengan menggunakan penghitungan persentase.

\section{HASIL DAN PEMBAHASAN \\ Hasil Penelitian}

Pada bagian ini akan sajikan deskripsi data teknik dasar bermain bulutangkis yang merupakan hasil pengukuran yang diberikan kepada siswa Sekolah Dasar Pembangunan Kota Padang menggunakan tes keterampilan dasar bermain bulutangkis untuk kategori pemula yang terdiri dari tes, servis, lob dan smash.

\section{a. Servis}

Berdasarkan pengukuran Servis yang telah dilakukan terhadap sampel, maka diperoleh skor tertinggi adalah sebesar 20 dan skor terendah 1, rata-rata 9.57, median 10, modus 4 dan standar deviasi sebesar 5.33. untuk lebih jelasnya hasil pengukuran kemampuan servis, dapat dilihat pada tabel 1.

Tabel 1. Hasil Pengukuran Kemampuan Servis

\begin{tabular}{|c|c|c|c|}
\hline Kelas Interval & Fa & Fr $(\mathbf{\%})$ & Klasifikasi \\
\hline $1-5$ & 4 & 28.57 & Kurang Sekali \\
\hline $6-10$ & 5 & 35.71 & Kurang \\
\hline $11-15$ & 3 & 21.43 & Sedang \\
\hline $16-20$ & 2 & 14.29 & Baik \\
\hline $21-25$ & 0 & 0.00 & Baik Sekali \\
\hline Jumlah & $\mathbf{1 4}$ & $\mathbf{1 0 0}$ & \\
\hline
\end{tabular}

Dari tabel 1 di atas maka dapat diketahui bahwa 4 orang siswa (28.57\%) memiliki kemampuan servis pada interval 1-5 dengan klasifikasi kurang sekali, 5 orang siswa (35.71\%) memiliki kemampuan servis pada interval 6-10 dengan klasifikasi kurang, dan 3 orang siswa $(21.43 \%)$ memiliki kemampuan servis pada pada interval 11-15 dengan klasifikasi sedang, dan 2 orang siswa (14.29\%) memiliki kemampuan servis pada interval 16-20 dengan klasifikasi baik serta tidak ada siswa (0\%) memiliki kemampuan servis pada interval 21-25 dengan klasifikasi baik sekali. Hasil pengukuran tersebut kemudian disajikan ke dalam diagram batang sebagai berikut: 


\section{MAJALAH ILMIAH}

http://1ppm.upiyptk.ac.id/ojs3/index.php/MAJALAHILMIAH/index

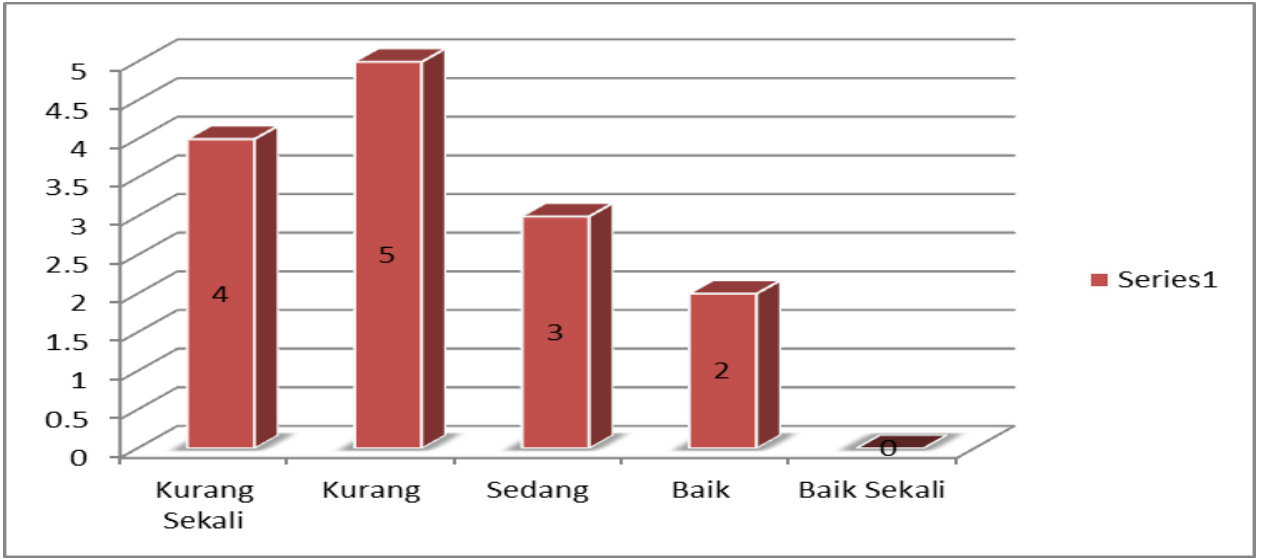

Grafik 1. Hasil Pengukuran Kemampuan Servis Sumber: data penelitian penulis

\section{b. Lob}

Berdasarkan pengukuran Lob yang telah dilakukan terhadap sampel, maka diperoleh skor tertinggi adalah sebesar 18 dan skor terendah 4, rata-rata 11, median 10, modus 18 dan standar deviasi sebesar 4.90. untuk lebih jelasnya hasil pengukuran kemampuan lob, dapat dilihat pada tabel 2.

Tabel 2. Hasil Pengukuran Kemampuan Lob

\begin{tabular}{|c|c|c|c|}
\hline Kelas Interval & Fa & Fr (\%) & Klasifikasi \\
\hline $1-5$ & 2 & 14.29 & Kurang Sekali \\
\hline $6-10$ & 6 & 42.86 & Kurang \\
\hline $11-15$ & 3 & 21.43 & Sedang \\
\hline $16-20$ & 3 & 21.43 & Baik \\
\hline $21-25$ & 0 & 0.00 & Baik Sekali \\
\hline Jumlah & $\mathbf{1 4}$ & $\mathbf{1 0 0}$ & \\
\hline
\end{tabular}

Dari tabel 2 di atas maka dapat diketahui bahwa 2 orang siswa (14.29\%) memiliki kemampuan lob pada interval 1-5 dengan klasifikasi kurang sekali, 6 orang siswa (42.86\%) memiliki kemampuan lob pada interval 6-10 dengan klasifikasi kurang, dan 3 orang siswa $(21.43 \%)$ memiliki kemampuan lob pada pada interval 11-15 dengan klasifikasi sedang, dan 3 orang siswa (21.43\%) memiliki kemampuan lob pada interval 16-20 dengan klasifikasi baik serta tidak ada siswa (0\%) memiliki kemampuan lob pada interval 21-25 dengan klasifikasi baik sekali. Hasil pengukuran tersebut kemudian disajikan ke dalam diagram batang sebagai berikut: 


\section{MAJALAH ILMIAH}

http://1ppm.upiyptk.ac.id/ojs3/index.php/MAJALAHILMIAH/index

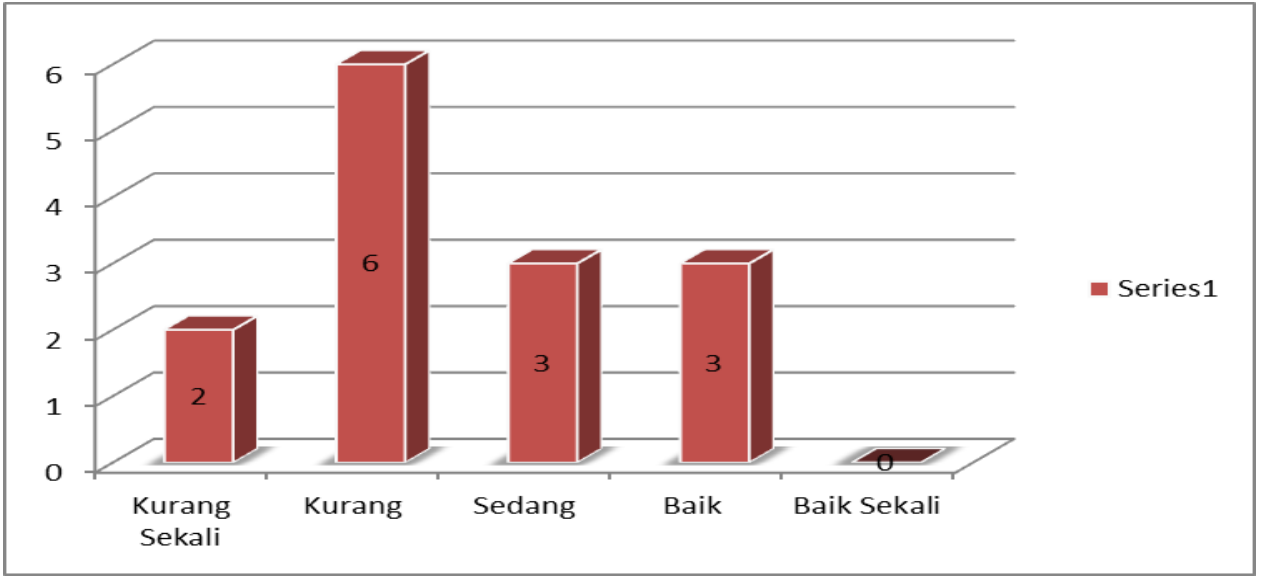

Grafik 2. Hasil Pengukuran Kemampuan Lob

\section{c. Smash}

Berdasarkan pengukuran Smash yang telah dilakukan terhadap sampel, maka diperoleh skor tertinggi adalah sebesar 23 dan skor terendah 1, rata-rata 16.14, median 18, modus 18 dan standar deviasi sebesar 5.38. untuk lebih jelasnya hasil pengukuran kemampuan smash, dapat dilihat pada tabel 3 .

Tabel 3. Hasil Pengukuran Kemampuan Smash

\begin{tabular}{|c|c|c|c|}
\hline Kelas Interval & Fa & Fr (\%) & Klasifikasi \\
\hline $1-5$ & 1 & 7.14 & Kurang Sekali \\
\hline $6-10$ & 0 & 0.00 & Kurang \\
\hline $11-15$ & 5 & 35.71 & Sedang \\
\hline $16-20$ & 6 & 42.86 & Baik \\
\hline $21-25$ & 2 & 14.29 & Baik Sekali \\
\hline Jumlah & $\mathbf{1 4}$ & $\mathbf{1 0 0}$ & \\
\hline
\end{tabular}

Dari tabel 3 di atas maka dapat diketahui bahwa 1 orang siswa (7.14\%) memiliki kemampuan smash pada interval 1-5 dengan klasifikasi kurang sekali, dan tidak ada siswa (0\%) memiliki kemampuan smash pada interval 6-10 dengan klasifikasi kurang, dan 5 orang siswa $(35.71 \%)$ memiliki kemampuan smash pada pada interval 11-15 dengan klasifikasi sedang, dan 6 orang siswa (42.86\%) memiliki kemampuan smash pada interval 16-20 dengan klasifikasi baik 2 orang siswa (14.29\%) memiliki kemampuan smash pada interval 21-25 dengan klasifikasi baik sekali. Hasil pengukuran tersebut kemudian disajikan ke dalam diagram batang sebagai berikut: 


\section{MAJALAH ILMIAH}

http://1ppm.upiyptk.ac . id/ojs3/index.php/MAJALAHILMIAH/index

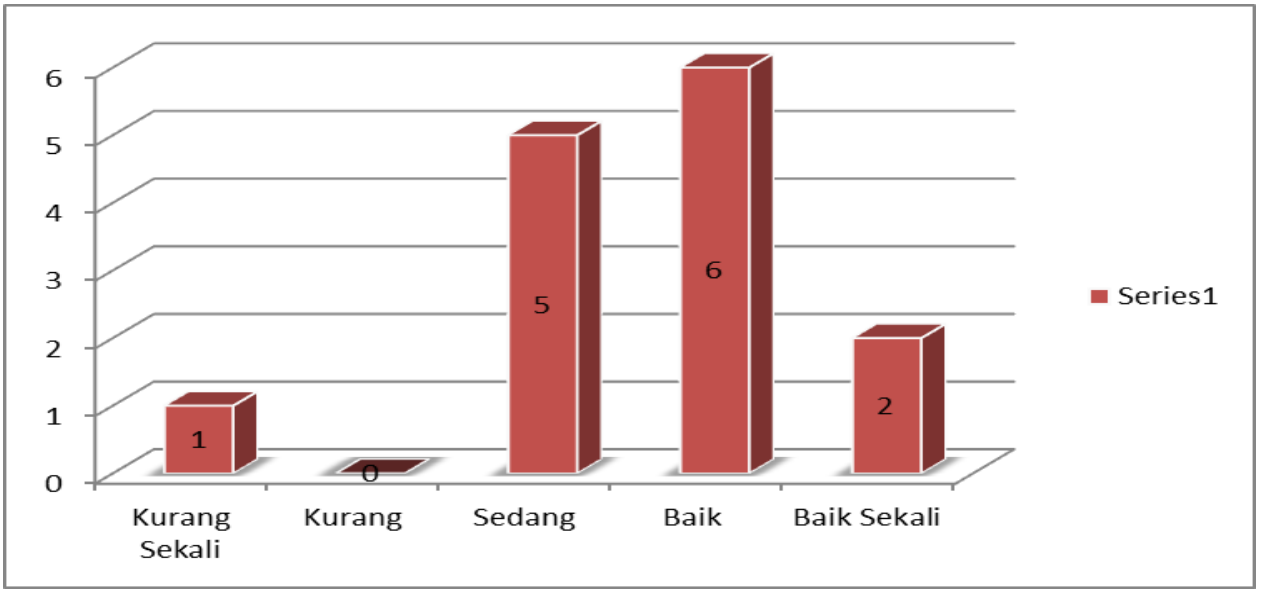

Grafik 3. Hasil Pengukuran Kemampuan Smash

d. Kemampuan Teknik Dasar Bulutangkis

Berdasarkan pengukuran kemampuan teknik Bulutangkis yang telah dilakukan terhadap sampel, maka diperoleh skor tertinggi adalah sebesar 17.67 dan skor terendah 8, rata-rata 12.24, median 12.17, modus 12 dan standar deviasi sebesar 2.62. untuk lebih jelasnya hasil pengukuran kemampuan teknik dasar Bulutangkis, dapat dilihat pada tabel 4.

Tabel 4. Hasil Pengukuran Teknik Dasar Bulutangkis

\begin{tabular}{|c|c|c|c|}
\hline Kelas Interval & Fa & Fr (\%) & Klasifikasi \\
\hline $1-5$ & 0 & 0.00 & Kurang Sekali \\
\hline $6-10$ & 4 & 28.57 & Kurang \\
\hline $11-15$ & 8 & 57.14 & Sedang \\
\hline $16-20$ & 2 & 14.29 & Baik \\
\hline $21-25$ & 0 & 0.00 & Baik Sekali \\
\hline Jumlah & $\mathbf{1 4}$ & $\mathbf{1 0 0}$ & \\
\hline
\end{tabular}

Dari tabel 4 di atas maka dapat diketahui bahwa tidak ada siswa (0\%) memiliki kemampuan teknik dasar Bulutangkis pada interval 1-5 dengan klasifikasi kurang sekali, dan 4 orang siswa (28.57\%) memiliki kemampuan teknik dasar Bulutangkis pada interval 6-10 dengan klasifikasi kurang, dan 8 orang siswa (57.14\%) memiliki kemampuan teknik dasar Bulutangkis pada pada interval 11-15 dengan klasifikasi sedang, dan 2 orang siswa (14.29\%) memiliki kemampuan teknik dasar Bulutangkis pada interval 16-20 dengan klasifikasi baik dan tidak ada siswa (0\%) memiliki kemampuan teknik dasar Bulutangkis pada interval 21-25 dengan klasifikasi baik sekali. Hasil pengukuran tersebut kemudian disajikan ke dalam diagram batang sebagai berikut: 


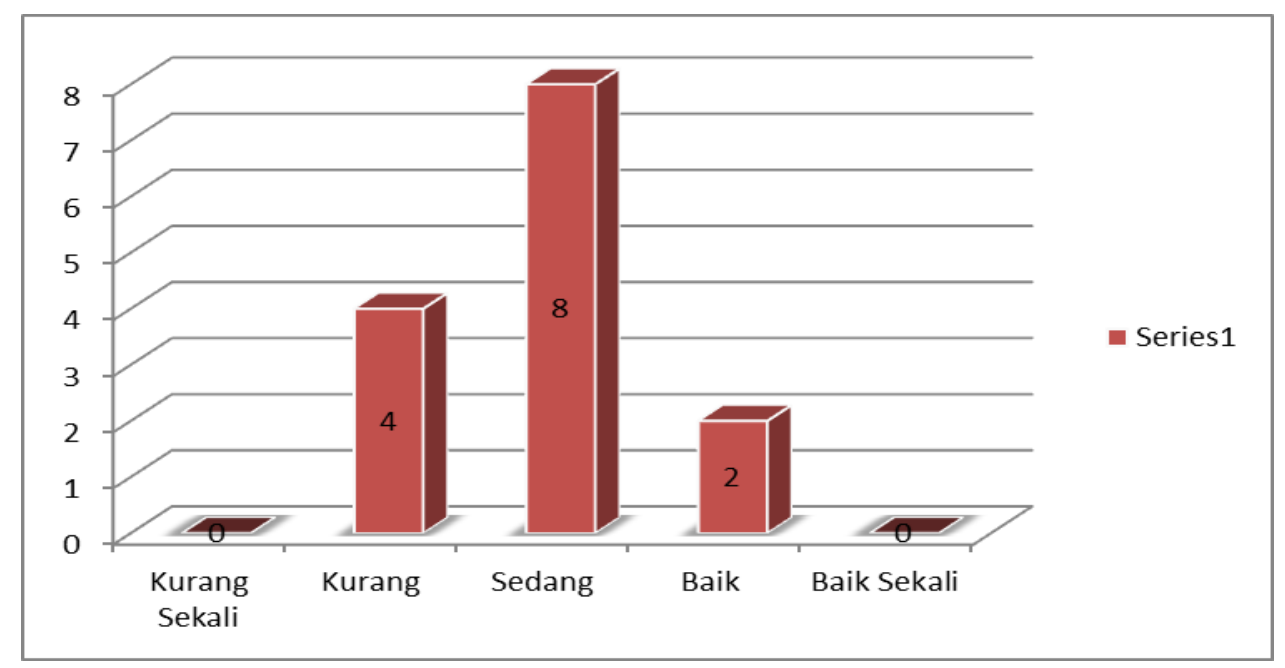

Grafik 4. Hasil Pengukuran Kemampuan Teknik Dasar Bulutangkis

\section{Pembahasan}

Berdasarkan hasil penelitian yang telah diuraikan di atas maka dapat diketahui bahwa sebagian besar siswa Sekolah Dasar Pembangunan Kota Padang memiliki kemampuan servis pada kategori kurang dengan persentase sebesar $35.71 \%$ dan kemampuan lob sebagian besar berada pada kategori kurang dengan persentase sebesar $42.86 \%$ dan kemampuan smash sebagian besar berada pada kategori baik dengan persentase sebesar $42.86 \%$ serta kemampuan teknik dasar bulutangkis secara keseluruhan sebagian besar berada pada kategori sedang dengan persentase sebesar $57.14 \%$.

Melihat hasil temuan tersebut tentunya hal ini perlu mendapatkan perhatian yang serius dalam rangka mencapai prestasi, karena untuk meraih prestasi maksimal pada olahraga maka dibutuhkan 4 unsur utama yaitu, kemampuan teknik, taktik, kondisi fisik dan mental (Syafruddin 2011;78). Dari 3 unsur teknik yang diukur dalam penelitian ini mempunyai nilai dan perannya masing dalam meraih prestasi pada cabang olahraga Bulutangkis.

a. Servis

Servis merupakan teknik yang digunakan untuk memulai pertandingan dalam olahraga Bulutangkis (Zarwan, 2011). Pada saat ini servis tidak hanya dianggap sebagai teknik untuk memulai pertandingan bahkan serangan sudah dimulai sejak pemain melakukan servis, oleh sebab sangat dituntut sekali penguasaan teknik servis yang baik bagi pemain mengharapkan prestasi pada cabang bulutangkis. Jika kemampuan servis ini masih berada pada kategori rendah maka dikhawtirkan pemain akan mengalami kesulitan untuk melakukan servis dengan baik, dan kalaupun pemain mampu melakukan servis itu akan lebih mudah untuk diantisipasi oleh lawan.

b. Lob

Lob adalah salah satu bentuk pukulan dalam permainan bulutangkis dengan tujuan untuk menerbangkan shuttlecock setinggi mungkin yang mengarah dan jatuh di bagian belakang lapangan lawan. Pukulan lob ini dapat dilakukan dari atas kepala (overhead) maupun dari bawah (underhand) baik dengan forehand maupun dengan backhand. Menurut Khairuddin (2001) pukulan lob tinggi merupakan pukulan yang sering digunakan untuk bertahan atau memperlambat tempo permainan. Dengan kemampuan lob yang baik, maka pemain akan mampu dengan mudah menempatkan shuttlecock pada sisi bagian belakang lapangan lawan, sehingga akan sulit untuk diraih oleh, sebaliknya jika pemain tidak memiliki kemampuan lob 
yang baik maka penampatan shuttlecock di area belakangan lapangan lawan akan sulit dilakukan sehingga akan memudahkan lawan untuk melakukan serangan terutama melakukan smash.

c. smash

Smash adalah pukulan overhead (atas) yang diarahkan ke bawah dan dilakukan dengan tenaga penuh. Pukulan ini dapat dilaksanakan secara tepat apabila penerbangan shuttlecock berada didepan atas kepala dan diarahkan dengan ditukikkan serta diterjunkan kebawah (Zarwan, 2017). Smash merupakan salah satu teknik serangan yang paling sulit untuk diantisipasi oleh lawan, namun untuk mampua melakukan smash yang baik sangat dibutuhkan kemampuan daya ledak otot lengan yang baik serta koordinasi yang tinggi. Smash yang dilakukan dengan kuat dan tepat cenderung akan menghasilkan poin bagi pemain, oleh sebab itu penting sekali bagi para pemain bulutangkis untu memiliki kemampuan smash yang baik agar dapat melakukan serangan dengan maksimal.

\section{SIMPULAN DAN SARAN}

\section{Simpulan}

Berdasarkan penjelesan pada bab sebelumnya maka dapat berikan beberapa simpulan dalam penelitian ini adalah sebagai berikut:

1. Sebagian besar siswa sekolah dasar pembangunan Kota Padang memiliki kemampuan servis pada kategori kurang.

2. Sebagian besar siswa sekolah dasar pembangunan Kota Padang memiliki kemampuan lob pada kategori kurang.

3. Sebagian besar siswa sekolah dasar pembangunan Kota Padang memiliki kemampuan smash pada kategori baik.

4. Sebagian besar siswa sekolah dasar pembangunan Kota Padang memiliki Saran kemampuan teknik dasar bulutangkis pada kategori sedang.

Berdasarkan simpulan di atas maka peneliti memberikan saran bagi:

1. Guru dan pembinan bulutangkis di sekolah dasar agar dapat memberikan perhatian yang lebih terhadap penguasaan kemampuan teknik dasar bulutangkis karena teknik merupakan elemen utama untuk meraih prestasi.

2. Siswa agar dapat mengikuti latihan dengan sungguh-sungguh agar latihan yang diberikan oleh guru dapat memberikan peningkatan terhadap kemampuan teknik dasar bulutangkis.

\section{REFERENSI}

Bompa, 1990. Periodization, Theory And Methodology Of Training. Fourth Edition. USA:Kendal/Hunt Publising Company. 


\section{MAJALAH ILMIAH}

http://1ppm.upiyptk.ac.id/ojs3/index.php/MAJALAHILMIAH/index

Ghazali Indra Putra C. 2016. Pengembangan Pembelajaran Teknik Dasar Bulutangkis Berbasis Multimetode Pada Atlet Usia 11 dan 12 tahun. Jurnal Keolahragaan. Volume 4- No. 2: 1-2

Khairuddin. 2001. Pedoman Permainan Bulutangkis. Fakultas Ilmu Keolahragaan Universitas Negeri Padang

Syafruddin 2011. Ilmu Kepelatihan Olahraga: Teori Dan Aplikasinya Dalam Pembinaan Olahraga. Padang. UNP Press

Tohar. (1992). Olahraga Pilihan Bulutangkis. Depdikbud: Jakarta

Zarwan. 2011. Bulutangkis. Fakultas Ilmu Keolahragaan Universitas Negeri Padang.

Zarwan. Hardiansyah, Sefri. 2017. Pengaruh media video dan media chart terhadap ketepatan smash Bulutangkis Siswa SD Negeri 52 Kuranji Padang. Jurnal: Penjakora Volume 4 No 1, 51-63 